\title{
GAD autoantibodies and epitope reactivities persist after diagnosis in latent autoimmune diabetes in adults but do not predict disease progression: UKPDS 77
}

\author{
M. Desai • C. A. Cull • V. A. Horton • M. R. Christie • \\ E. Bonifacio • V. Lampasona • P. J. Bingley • \\ J. C. Levy • I. R. Mackay • P. Zimmet • R. R. Holman • \\ A. Clark
}

Received: 29 March 2007 / Accepted: 14 May 2007 / Published online: 27 July 2007

(C) Springer-Verlag 2007

\begin{abstract}
Aims/hypothesis Latent autoimmune diabetes in adults (LADA) is a slowly progressive form of autoimmune diabetes, with autoantibodies to islet proteins developing in older patients who have no immediate requirement for insulin therapy. Markers of its clinical course are uncharacterised. The aim of this study was to determine whether persistence of, or changes in, GAD65 autoantibodies (GADAs) in the LADA patients who participated in the United Kingdom Prospective Diabetes Study (UKPDS) were associated with disease progression or insulin requirement.

Methods GADA levels and their relative epitope reactivities to $\mathrm{N}$-terminal, middle and $\mathrm{C}$-terminal regions of
\end{abstract}

Electronic supplementary material The online version of this article (doi:10.1007/s00125-007-0745-6) contains supplementary material, which is available to authorised users.

M. Desai · V. A. Horton · J. C. Levy · A. Clark

Diabetes Research Laboratories, Oxford Centre for Diabetes,

Endocrinology and Metabolism, University of Oxford,

Oxford, UK

\section{A. Cull • R. R. Holman}

Diabetes Trials Unit, Oxford Centre for Diabetes,

Endocrinology and Metabolism, University of Oxford,

Oxford, UK

\section{R. Christie}

Beta cell Development and Function Group, Division of

Reproductive Health, Endocrinology and Development,

King's College London,

Guy's Campus,

London, UK

E. Bonifacio $\cdot$ V. Lampasona

Immunology of Diabetes Unit, San Raffaele Scientific Institute,

Milan, Italy human GAD65 were determined in 242 UKPDS patients who were GADA-positive at diagnosis; samples taken after $0.5,3$ and 6 years of follow-up were tested using a radiobinding assay. Comparisons were made of GADA status with clinical details and disease progression assessed by the requirement for intensified glucose-lowering therapy. Results GADA levels fluctuated between 0.5 and 6 years but persisted in 225 of 242 patients. No association of GADA levels with disease progression or insulin requirement was observed. Antibody reactivity was directed to Cterminal and middle epitopes of GAD65 in $>70 \%$ patients, and the N-terminal in $<9 \%$. There were no changes in epitope reactivity pattern over the 6 year follow-up period, nor any association between epitope reactivity and insulin requirement.

\section{P. J. Bingley}

Diabetes and Metabolism Unit, Division of Medicine,

University of Bristol, Bristol, UK

\section{R. Mackay}

Department of Biochemistry and Molecular Biology,

Monash University,

Clayton, VIC, Australia

\section{P. Zimmet}

International Diabetes Institute,

Caulfield, VIC, Australia

A. Clark $(\bowtie)$

Diabetes Research Laboratories,

Oxford Centre for Diabetes,

Endocrinology and Metabolism,

Churchill Hospital,

Headington, Oxford OX3 7LS, UK

e-mail: anne.clark@drl.ox.ac.uk 
Conclusions/interpretation GADAs persist for 6 years after diagnosis of LADA, but levels and reactivity to different GAD65 epitopes are not associated with disease progression.

Keywords Antibody persistence - Clinical progression . GAD antibodies - Latent autoimmune diabetes in adults . Type 1 diabetes

$\begin{array}{ll}\text { Abbreviations } & \\ \text { HOMA \%B } & \text { HOMA beta cell function } \\ \text { HOMA \%S } & \text { HOMA insulin sensitivity } \\ \text { DASP } & \begin{array}{l}\text { Diabetes Antibody Standardization } \\ \text { Program }\end{array} \\ \text { FPG } & \text { fasting plasma glucose } \\ \text { GADA } & \text { GAD65 autoantibody } \\ \text { HOMA } & \text { homeostasis model assessment } \\ \text { IA-2A } & \text { islet-antigen 2 antibody } \\ \text { ICA } & \text { islet cell autoantibody } \\ \text { IQR } & \text { interquartile range } \\ \text { JDF } & \text { Juvenile Diabetes Federation } \\ \text { LADA } & \text { latent autoimmune diabetes in adults } \\ \text { NCEP ATP III } & \text { National Cholesterol Education } \\ & \text { Program Adult Treatment Panel III } \\ \text { UKPDS } & \text { United Kingdom Prospective Diabetes } \\ & \text { Study }\end{array}$

\section{Introduction}

Latent autoimmune diabetes in adults (LADA) has been described as a slowly progressive form of type 1 diabetes [1]. The late age of presentation and absence of acute clinical symptoms (weight loss, ketosis, immediate insulin requirement) of patients with LADA often leads to their diagnosis with type 2 diabetes. However, at diagnosis, the presence in these patients of circulating autoantibodies to islet cell cytoplasm (ICAs) [2], the enzyme GAD65 (GADAs) and to a lesser extent, islet-antigen 2 (IA-2As) [3], suggests an underlying autoimmune pathology. This is consistent with the known predisposition for LADA conferred by the HLA gene region [4, 5]. In childhoodonset type 1 diabetes, multiple autoantibody positivity at diagnosis appears to associate with a more aggressive clinical course after onset [6].

Autoantibody measurements in patients at diagnosis of type 2 diabetes recruited into the United Kingdom Prospective Diabetes Study (UKPDS) have shown that $\sim 12 \%$ were antibody-positive (LADA). These LADA patients became insulin-requiring sooner than did those who were antibodynegative [3, 7]. Identification of markers associated with more rapid disease progression in LADA patients could assist with maintenance of good glycaemic control and hence avoidance of diabetic complications. However, the persistence of autoantibodies after diagnosis, the clinical utility of their levels or GAD65 epitope patterns have not been assessed in a large LADA cohort.

To investigate GADA persistence and the clinical relevance of GADA levels over time in LADA, antibodypositive UKPDS patients were examined over a 6 year period. We assessed whether GADAs persisted over this period and if fluctuation in levels or GAD65 epitope reactivities were associated with clinical data. The UKPDS randomised patients to glucose-lowering monotherapies [8], irrespectively of their autoantibody status, with strict protocol-defined monotherapy failure [9]. This provides a unique opportunity to examine objectively in antibodypositive patients the relationship of GADAs after diagnosis to disease progression; this was assessed as the time from diagnosis to failure of monotherapy or the clinical need to commence insulin therapy.

\section{Methods}

Patients The UKPDS was a randomised controlled trial designed to evaluate the efficacy in type 2 diabetes of different therapeutic approaches (diet, oral agents, insulin) to control hyperglycaemia and reduce the risk of diabetic complications. Newly diagnosed patients $(n=5,102)$, aged 25-65 years, were recruited by general practitioner referral from 23 clinical centres based in England, Northern Ireland and Scotland. The study was performed in accordance with the principles of the Declaration of Helsinki. All patients gave informed consent and the protocol received local research ethics committee approval. The UKPDS design and protocol has been previously reported [8]. There were 526 UKPDS patients who were self-reported white Caucasians and positive for ICAs and/or GADAs and/or IA2As at diagnosis [3] and 3,619 white Caucasian patients who were negative for all autoantibodies at diagnosis presented for comparison (see Electronic supplementary material [ESM] Table 1 and ESM Fig. 1).

GADA measurements At diagnosis, 443 of 526 antibodypositive patients were shown to be GADA-positive [3]. Of these, the current cohort of 242 participants were GADApositive at diagnosis and had plasma samples available at time points $(0.5,3$ and 6 years after diagnosis) with at least one being GADA-positive (see ESM Fig. 1). Samples taken at 0.5 years were assayed as insufficient plasma remained available from samples taken at diagnosis. In this group of 242 patients, comparisons were made of GADA levels determined previously in samples taken at diagnosis with those taken at 0.5 years in this study and at 3 and 6 years post-diagnosis (see ESM Fig. 2) 
Plasma GADA levels were determined with a radiobinding assay using ${ }^{35} \mathrm{~S}$-labelled human GAD65 as antigen which was validated in the 2003 Diabetes Antibody Standardization Program (DASP 2003) [10, 11]. GAD65 was produced by in vitro transcription/translation of human GAD65 (also known as GAD2) cDNA using a rabbit reticulocyte lysate (Promega, Madison, WI, USA) and $\mathrm{L}-\left[{ }^{35} \mathrm{~S}\right]$ methionine (Amersham Biosciences, Little Chalfont, Bucks, UK). Autoantibody concentrations were calculated in each experiment from a standard curve constructed using serum from a patient with type 1 diabetes, which itself had been standardised against WHO standard serum provided in the DASP 2003 workshop. GADA levels are presented as WHO units $/ \mathrm{ml}$. Samples with GADA levels greater than the highest standard (173.5 WHO units $/ \mathrm{ml}$ ) were diluted to fall on the linear part of the standard curve. Assay sensitivity was $86 \%$ and specificity was $94 \%$ at the 15 WHO units $/ \mathrm{ml}$ cut-off level for positivity determined in the DASP workshop. Plasma samples $(n=100)$ from unrelated, nondiabetic individuals in the Diabetes in Families Study of similar age to the LADA patients were assayed to establish the cut-off level for the GADA radiobinding assay.

GAD65 epitope reactivity measurements Reactivity to fulllength human GAD67 and to conformational epitopes of human GAD65 was determined by radiobinding assays using GAD67 and GAD67/65 chimeric fusion proteins as bait. The fusion proteins comprised GAD65 epitopes: (1) at the N-terminal (GAD65 ${ }_{1-95} /$ GAD67 $_{102-593}$ ); (2) in the middle region (GAD67 ${ }_{1-243} / \mathrm{GAD}_{235-442} / \mathrm{GAD}_{24}$ 443-593); or (3) at the C-terminal (GAD67 $1-452 /$ GAD65 $_{445-585}$ ) $[10,12]$. Reactivities to GAD65 epitopes and GAD67 were expressed as arbitrary units relative to a standard prepared from samples from patients with type 1 diabetes or Stiff-Person syndrome. The cut-off level for positivity was determined for each assay as the mean +3 SDs in arbitrary units measured in samples from 100 non-diabetic individuals.

Clinical and biochemical measurements Age, sex, ethnicity and height were recorded at diagnosis and fasting plasma glucose (FPG), fasting plasma insulin (FPI), $\mathrm{HbA}_{1 \mathrm{c}}$ and weight after the 3-4 month dietary run-in. FPG, FPI and $\mathrm{HbA}_{1 \mathrm{c}}$ levels were assayed as described previously [13]. Homeostasis model assessment (HOMA) beta cell function (HOMA \%B) and insulin sensitivity (HOMA \%S) were derived from simultaneous FPG and FPI measurements [14, 15] using the HOMA Calculator (available at http://www. dtu.ox.ac.uk/HOMA, last accessed in May 2007). The presence or absence of the metabolic syndrome was assessed using the National Cholesterol Education Program Adult Treatment Panel III (NCEP ATP III) definition [16].

Disease progression This was assessed both in terms of monotherapy failure and in insulin requirement. 'Monotherapy failure' was defined as the UKPDS protocol-specified requirement to add second-line therapy when glycaemic control became unacceptable (FPG $>15 \mathrm{mmol} / \mathrm{l}$ or persistent hyperglycaemic symptoms) in patients randomised to diet alone, sulfonylurea, metformin (overweight patients only) or basal insulin [9]. 'Insulin requirement' was defined as the

Table 1 Comparison of clinical characteristics at diagnosis of 242 GADA-positive white Caucasian UKPDS patients with antibody-negative (type 2 diabetic) individuals

\begin{tabular}{|c|c|c|c|}
\hline $\begin{array}{l}\text { Clinical characteristic at } \\
\text { diagnosis }\end{array}$ & GADA study & $\begin{array}{l}\text { Antibody-negative at diagnosis } \\
\text { (type } 2 \text { diabetes) }\end{array}$ & $p$ value (GADA study vs type 2 diabetes) ${ }^{\mathrm{a}}$ \\
\hline$n$ & 242 & 3,619 & \\
\hline Age (years) ${ }^{b}$ & $47.0(10.8)$ & $53.6(83)$ & $<0.00001$ \\
\hline Sex $(\%$ male $)$ & 53 & 58 & 0.12 \\
\hline $\mathrm{FPG}(\mathrm{mmol} / \mathrm{l})^{\mathrm{c}}$ & $11.4(7.9-15.5)$ & $8.1(6.7-10.5)$ & $<0.00001$ \\
\hline $\operatorname{HbA}_{1 \mathrm{c}}(\%)^{\mathrm{c}}$ & $9.0(7.0-10.7)$ & $7.0(6.0-8.4)$ & $<0.00001$ \\
\hline Weight $(\mathrm{kg})^{\mathrm{b}}$ & $68.1(13.2)$ & $79.0(16.3)$ & $<0.00001$ \\
\hline BMI $\left(\mathrm{kg} / \mathrm{m}^{2}\right)^{\mathrm{b}}$ & $23.8(4.4)$ & $28.1(5.5)$ & $<0.00001$ \\
\hline Systolic BP $(\mathrm{mmHg})^{\mathrm{b}}$ & $125(17)$ & $137(20)$ & $<0.00001$ \\
\hline Diastolic BP $(\mathrm{mmHg})^{\mathrm{b}}$ & $79(11)$ & $83(11)$ & $<0.00001$ \\
\hline HOMA $\% \mathrm{~B}^{\mathrm{c}}$ & $30(15-58)$ & $57(36-85)$ & $<0.00001$ \\
\hline HOMA $\% \mathrm{~S}^{\mathrm{c}}$ & $73(48-101)$ & $51(36-74)$ & $<0.00001$ \\
\hline $\begin{array}{l}\text { Plasma triacylglycerols } \\
(\mathrm{mmol} / \mathrm{l})^{\mathrm{d}}\end{array}$ & $1.19(0.73-1.95)$ & $1.63(0.99-2.69)$ & $<0.00001$ \\
\hline Metabolic syndrome $^{\mathrm{e}}, n(\%)$ & $106(44 \%)$ & $2784(77 \%)$ & $<0.00001$ \\
\hline
\end{tabular}

${ }^{a}$ Using a two-sample $t$ test or Wilcoxon sign-rank test, or $\chi^{2}$ test for proportions

${ }^{\mathrm{b}}$ Mean (SD)

${ }^{\mathrm{c}}$ Median (IQR)

${ }^{\mathrm{d}}$ Geometric mean (1 SD interval)

${ }^{\mathrm{e}} \mathrm{NCEP}$ ATP III definition with BMI $>27 \mathrm{~kg} / \mathrm{m}^{2}$ (men) or $>29 \mathrm{~kg} / \mathrm{m}^{2}$ (women) 
clinical need to commence insulin therapy in patients not allocated to insulin monotherapy whose glycaemic control became unacceptable despite maximally tolerated combination sulfonylurea and metformin therapy.

Statistical method Statistical analyses were performed using SAS versions 8.2 and 9.1.3 (SAS Institute, Cary, $\mathrm{NC}$, USA). Data are reported as mean (SD), geometric mean (1 SD interval), median (interquartile range [IQR]) or percentages according to the distribution of the data. For independent samples, two-sample $t$ tests or Wilcoxon signrank tests were used to compare continuously distributed data, according to normality of data distributions, and $\chi^{2}$ or Fisher's exact tests were used for categorical comparisons. For paired samples, paired-sample $t$ tests or the sign test were used as appropriate. Spearman's rank correlation coefficients were used to assess associations between continuous variables. $Z$ tests or $\chi^{2}$ goodness of fit tests were used to determine whether the 242 patients of the GADA-positive subset were representative of the 443 UKPDS LADA group previously identified [3, 7]. Kaplan-Meier analysis of time to progression, or time to insulin requirement, in relation to thirds of GADA level at 0.5 years with a log-rank test was performed. A proportional hazards model was used to estimate relative risk $(95 \% \mathrm{CI})$, unadjusted and adjusted for randomised therapy. A conventional statistical significance of $p<0.05$ was used throughout and $p$ values between 0.05 and 0.0001 are presented to two significant figures. No adjustment for multiple testing was carried out.

\section{Results}

Clinical characteristics of patients Clinical characteristics at diagnosis of UKPDS patients included in the present study $(n=242)$ and those who were antibody-negative at diagnosis $(n=3,619)$ are shown in Table 1 . The present GADA-positive study cohort were significantly younger and leaner and had higher median FPG, $\mathrm{HbA}_{1 \mathrm{c}}$ and HOMA $\% \mathrm{~S}$ and lower HOMA \%B and mean BP than GADAnegative patients in the UKPDS (Table 1). Comparisons between this subgroup and the larger GADA-positive at diagnosis cohort $(n=443)$ are reported in the ESM. a

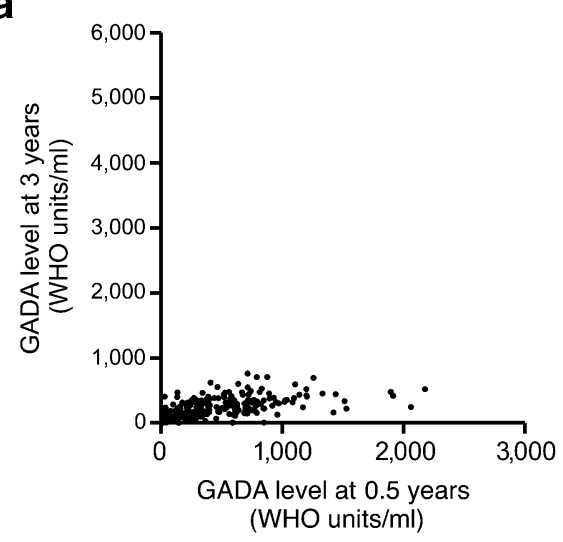

b

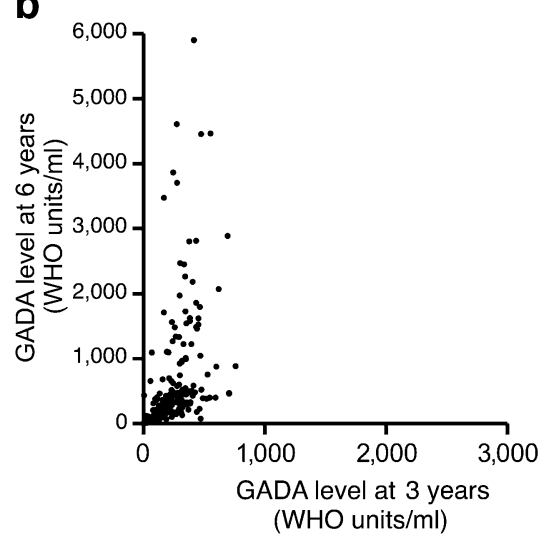

e

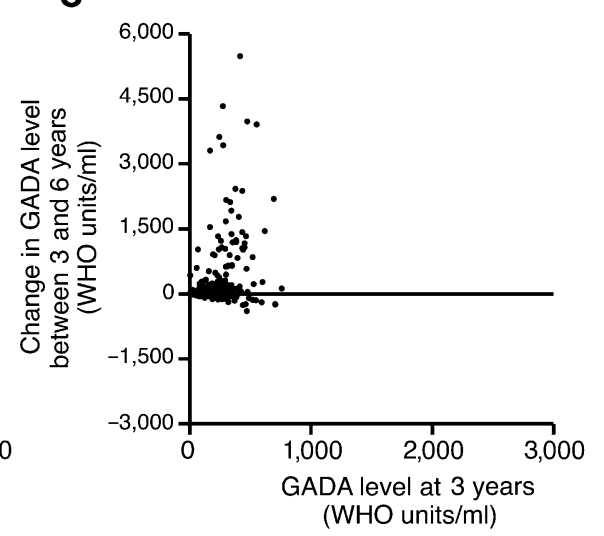

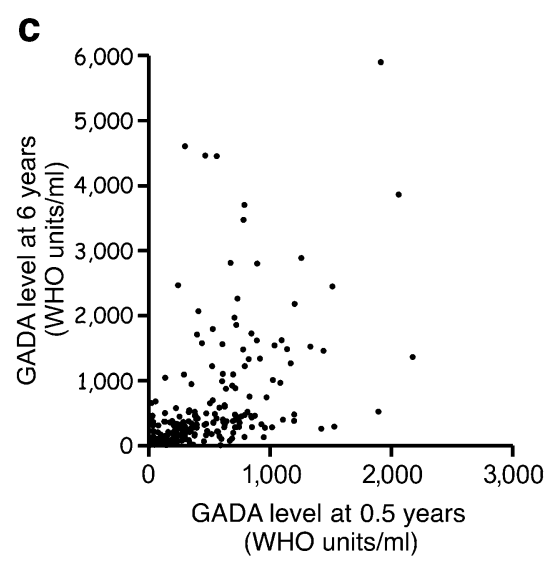

f

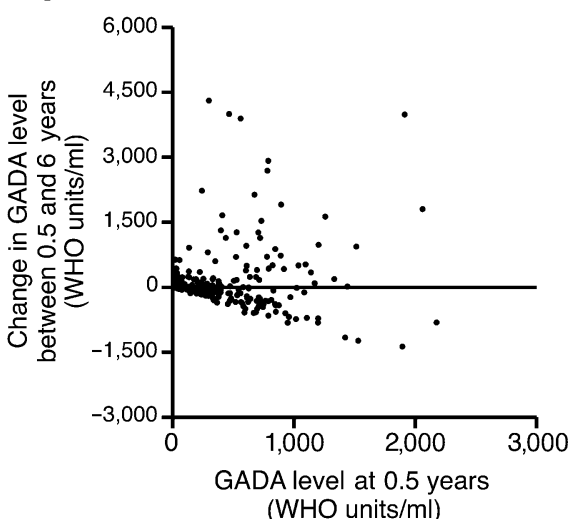

change in level for each patient between 0.5 years and 3 years. e Level at 3 years vs change in level between 3 years and 6 years. f Level at 0.5 years vs change in level between 0.5 years and 6 years 
GADA persistence GADA levels were above the 15 WHO units/ml cut-off level in 237, 231 and 237 of the 242 patients at $0.5,3$ and 6 years, respectively. Median (IQR) GADA levels fell from 331 (134-674) WHO units/ml at 0.5 years to 199 (96-318) WHO units/ml at 3 years, and then rose to $284(107-518) \mathrm{WHO}$ units $/ \mathrm{ml}$ at 6 years. Although GADA levels were lower at 3 years than at 0.5 or 6 years, those patients with higher values at 0.5 years tended to remain high at 3 and 6 years and those with lower values at 0.5 years remained low (Fig. 1a-c). Fewer patients had levels $>1,000$ units $/ \mathrm{ml}$ at 3 years compared with 0.5 years and 6 years (Fig. 1a,c). The median change (IQR) in GADA level between 0.5 and 3 years was -100 $(-381$ to -1$)$ WHO units $/ \mathrm{ml}(p<0.0001)$, reflecting a decrease in GADA levels for most patients (Fig. 1). Between 3 and 6 years there was a net increase in level by a median (IQR) of 53 ( -9 to 243 ) WHO units/ml ( $p<$ $0.0001)$. This was influenced by a small group ( $\sim 50$ patients) in whom GADA levels increased substantially; the clinical characteristics of these patients at diagnosis were similar to those in whom GADA levels remained relatively unchanged (data not shown). Levels at 0.5 and 6 years were similar with the median change over this time of -3 ( -138 to 150$)$ WHO units $/ \mathrm{ml}(p=0.89)$ (Fig. 1f).

Relationship of GADA level to clinical characteristics and actual therapy No significant associations were found between GADA levels at 0.5 years and age, $\mathrm{FPG}, \mathrm{HbA}_{1 \mathrm{c}}$,
HOMA \%B, HOMA \%S, systolic BP, BMI or the presence of the metabolic syndrome at diagnosis, but GADA levels at 0.5 years were correlated with plasma triacylglycerols $\left(r_{\mathrm{s}}=-0.16, p=0.017\right)$. Similarly, no significant associations were found between GADA levels at 3 and 6 years and concomitant $\mathrm{FPG}, \mathrm{HbA}_{1 \mathrm{c}}$, BMI or systolic $\mathrm{BP}$ values. There were no differences in GADA levels between patients allocated to diet, oral agents or insulin therapy in the UKPDS protocol and no association was seen at any time point between GADA levels and patients' actual therapy at $0.5,3$ or 6 years; the numbers of patients receiving diet, oral or insulin therapy at 0.5 years were $n=$ 48,100 and 94 , at 3 years were $n=14,71$ and 157, and at 6 years were $n=10,62$ and 180, respectively.

Relationship of GADA level to disease progression At 0.5 years, monotherapy failure had occurred in 56 GADA-positive patients who were younger, had a lower BMI and HOMA \%B and of whom fewer had the metabolic syndrome compared with those remaining on monotherapy (Table 2). They also had higher median (IQR) GADA levels at 0.5 years with 437 (236-789) vs 297 (104626) WHO units $/ \mathrm{ml}$, respectively $(p=0.005)$. No significant difference was seen in time to monotherapy failure for patients grouped according to thirds of GADA level at 0.5 years $(15,208 ; 208,532$; and $\geq 532$ WHO units $/ \mathrm{ml})$ (log-rank $p=0.56$ ) (Fig. 2a). Hazard ratios $(95 \%$ CI) for progression of patients in the middle and highest thirds

Table 2 Clinical characteristics of patients at randomisation and at 0.5 years according to their monotherapy failure status at 0.5 years

\begin{tabular}{|c|c|c|c|}
\hline & Remained on monotherapy & Monotherapy failure $^{\mathrm{a}}$ & $p$ value \\
\hline$n$ & 186 & 56 & \\
\hline GADA (WHO units $/ \mathrm{ml}$ ) at 0.5 years ${ }^{\mathrm{b}}$ & $297(104-626)$ & 437 (236-789) & 0.0054 \\
\hline Sex $(\%$ male $)$ & 54 & 53 & 0.960 \\
\hline Age $(\text { years })^{c}$ & $47.8(10.7)$ & $44.1(10.8)$ & 0.022 \\
\hline FPG at randomisation $(\mathrm{mmol} / \mathrm{l})^{\mathrm{b}}$ & $9.4(7.4-15.0)$ & $14.3(12.8-18.0)$ & $<0.0001$ \\
\hline FPG at 0.5 years $(\mathrm{mmol} / \mathrm{l})^{\mathrm{b}}$ & $7.5(6.3-9.1)$ & $8.5(5.7-11.3)$ & 0.29 \\
\hline $\mathrm{HbA}_{1 \mathrm{c}}$ at randomisation $(\%)^{\mathrm{b}}$ & $8.0(6.5-10.2)$ & $10.7(9.7-12.1)$ & $<0.0001$ \\
\hline $\mathrm{HbA}_{1 \mathrm{c}}$ at 0.5 years $(\%)^{\mathrm{b}}$ & $6.5(5.8-8.0)$ & $7.6(6.6-8.9)$ & 0.0046 \\
\hline HOMA $\% \mathrm{~B}$ at randomisation $^{\mathrm{c}}$ & $33(15-76)$ & $13(7-24)$ & $<0.0001$ \\
\hline $\mathrm{HOMA} \% \mathrm{~S}$ at randomisation $^{\mathrm{c}}$ & $73(39-134)$ & $72(36-142)$ & 0.93 \\
\hline BMI at randomisation $\left(\mathrm{kg} / \mathrm{m}^{2}\right)^{\mathrm{d}}$ & $24.3(4.5)$ & $22.1(3.2)$ & 0.00077 \\
\hline BMI at 0.5 years $\left(\mathrm{kg} / \mathrm{m}^{2}\right)^{\mathrm{d}}$ & $24.5(4.5)$ & $23.5(3.4)$ & 0.12 \\
\hline Systolic BP at randomisation $(\mathrm{mmHg})^{\mathrm{d}}$ & $126(17)$ & $122(18)$ & 0.095 \\
\hline Systolic BP at 0.5 years $(\mathrm{mmHg})^{\mathrm{d}}$ & $127(18)$ & $122(18)$ & 0.10 \\
\hline Plasma triacylglycerols at randomisation $(\mathrm{mmol} / \mathrm{l})^{\mathrm{c}}$ & $1.19(0.74-1.91)$ & $1.21(0.70-2.08)$ & 0.84 \\
\hline Plasma triacylglycerols at 0.5 years $(\mathrm{mmol} / \mathrm{l})^{\mathrm{c}}$ & $1.09(0.68-1.73)$ & $0.95(0.61-1.50)$ & 0.074 \\
\hline Metabolic syndrome, $n(\%)^{\mathrm{e}}$ & $56(30 \%)$ & $5(9 \%)$ & 0.0014 \\
\hline
\end{tabular}

${ }^{a}$ Monotherapy failure is defined as the UKPDS protocol-specified requirement to add a second-line therapy when glycaemic control became unacceptable (FPG $>15 \mathrm{mmol} / \mathrm{l}$ or persistent hyperglycaemic symptoms) [9]

${ }^{\mathrm{b}}$ Median (IQR)

${ }^{\mathrm{c}}$ Geometric mean (1 SD interval)

${ }^{\mathrm{d}}$ Mean (SD)

${ }^{\mathrm{e}}$ NCEP ATP III definition 
a

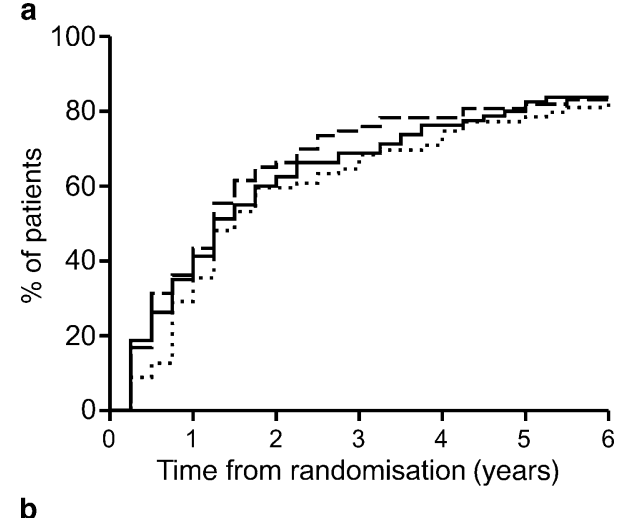

b

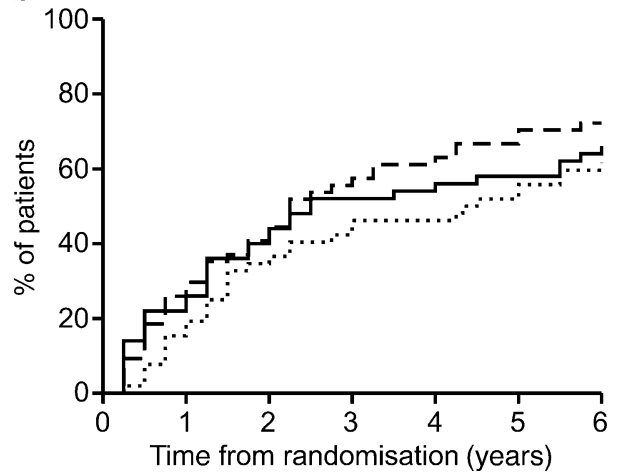

Fig. 2 Disease progression in relationship to GADA levels. KaplanMeier plots of the proportion of patients classified according to thirds of the GADA level at 0.5 years. a Monotherapy failure; $p=0.56$ (log-rank test). b Requiring insulin therapy within the first 6 years from diagnosis of diabetes; $p=0.37$ (log-rank test). Dotted line, 15-208 GADA units $/ \mathrm{ml}$; solid line, 208-532 GADA units $/ \mathrm{ml}$; broken line, $\geq 532$ GADA units/ml

relative to the lowest were $1.11(0.79-1.56, p=0.56)$ and 1.14 $(0.61-1.60, p=0.45)$, respectively (adjusted for therapy at randomisation).

In the 156 GADA-positive patients who had not been randomised to insulin therapy, GADA levels at 0.5 years were not predictive of their clinical need to commence insulin therapy over 6 years with no significant difference for patients classified by thirds of GADA levels at 0.5 years in their time to insulin requirement or their risk of requiring insulin (log-rank $p=0.37)$ (Fig. 2b). Hazard ratios $(95 \%$ CI) for patients requiring insulin therapy within the middle and upper thirds, relative to the lowest, were $1.12(0.68-1.83$, $p=0.66)$ and $1.34(0.84-2.15, p=0.22)$, respectively (adjusted for therapy at randomisation).

GAD65 epitope reactivity Since construction of the chimeras for expression of GAD65 epitopes incorporated regions of GAD67, all samples reactive with human GAD67 were omitted from the epitope analyses. One hundred and seven patients in the 242 GADA-positive group were reactive against full-length GAD67. No reactivity to any of the epitopes of GAD65 could be detected in 15,14 and $21 \%$ of samples at 0.5, 3 and 6 years, respectively (Fig. 3). The most frequent epitope pattern was reactivity to both the C-terminal and middle regions $(53,54$ and $52 \%$ patients positive at 0.5 , 3 and 6 years, respectively) (Fig. 3); N-terminal reactivity was least frequent $(<9 \%)$ and was not related to GADA levels. Epitope patterns did not change significantly with time; $68 \%(n=93)$ and $50 \%(n=67)$ of patients were positive for middle and C-terminal epitopes, respectively, at all three time points. GADA levels were positively associated with reactivity to the $\mathrm{C}$-terminal and middle epitope regions at all time points (all $p<0.0001)$.

No difference was seen in the time to monotherapy failure in patients with C-terminal or middle region reactivity alone at 0.5 years $(n=35)$ compared with those with combined reactivity $(n=73)$. Similarly, the time to requiring insulin in patients not randomised to insulin therapy $(n=70 / 135)$ did not differ between those with $\mathrm{C}$-terminal or middle region reactivity at 0.5 years $(n=20)$ compared with those with combined reactivity $(n=50)$.

\section{Discussion}

Persistence of GADAs after diagnosis This is the first large longitudinal study to assess the persistence of GADA positivity over 6 years after diagnosis in LADA. Our data support a smaller Swedish study, which showed that GADA positivity persists for up to 12 years in LADA [17]. As
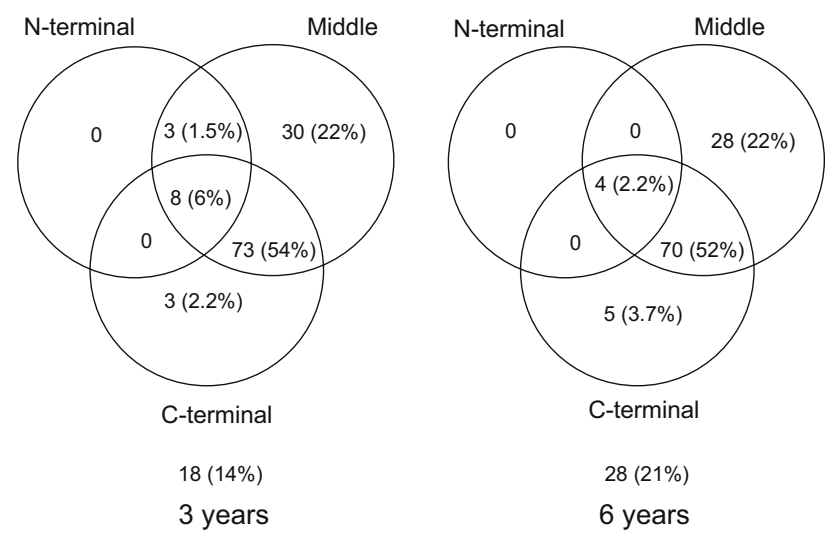

Fig. 3 Distribution of GAD65 epitope recognition patterns at $0.5,3$ and 6 years after diagnosis in 135 patients who were GADA-positive and GAD67negative and had samples available at the three time points. N-terminal aminoterminal region of GAD65; middle middle region of GAD65; C-terminal carboxyterminal region of GAD65 [10]

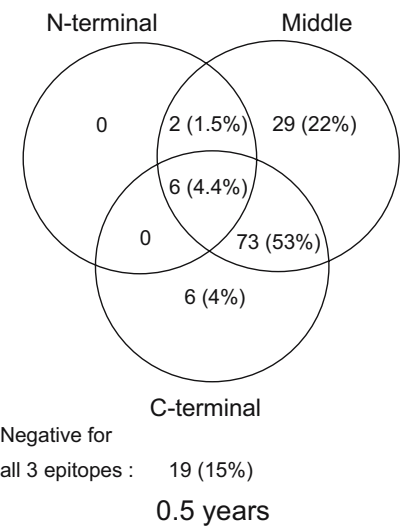

0.5 years 
found in type 1 diabetes, changes in positivity were rare and were associated with lower GADA levels [18]. GADA persistence could be related to both antigen-specific and environmental factors. Measurement of HOMA \%B values at diagnosis (Table 1) suggested that there were low existing levels of functional beta cells and possibly GAD antigen in our LADA cohort, as observed in type 1 diabetes [19]. If pancreatic islet antigen availability is related to GADA persistence, slow pancreatic beta cell destruction in LADA (compared with a more rapid loss observed in childhood-onset type 1 diabetes) could sustain the humoral response directed against GAD65. Indeed, more residual beta cells have been identified in post-mortem material in adult-onset autoimmune diabetes compared with childhoodonset disease [20,21].

GADA positivity The clinical characteristics at diagnosis of this subgroup of 242 GADA-positive patients suggested that they represented a more precise clinical and biochemical delineation of LADA patients compared with the overall autoantibody-positive UKPDS LADA group previously reported (see ESM) [3]. The difference in the proportion of GADA-positive patients requiring insulin by 6 years in this study (73\%) compared with those previously reported for UKPDS LADA (33 and 38\%) [7, 22] could be due to differences in ascertainment by antibody assays of variable sensitivities [23].

Fluctuations of GADA levels after diagnosis GADA levels fluctuated over time in individual LADA patients in a manner similar to that reported in children with type 1 diabetes [24, 25]; some increased with time, others decreased, while others remained stable. A consistent decrease in GADA levels was observed across the group between 0.5 years and 3 years; this coincided with a large proportion of patients in the LADA cohort requiring insulin treatment by this time $(65 \%$, Table 2). While the reduction in levels could, in part, be explained by regression to the mean, this effect is unlikely to account for all of the change. The average increase in level between 3 and 6 years after diagnosis was influenced by a small proportion of patients showing much increased levels over this time period, whereas in the majority of patients levels stabilised after the 3 year fall.

Clinical relevance of GADA measurement in the postdiagnosis period The persistence of GADA positivity after diagnosis indicates that this measurement has diagnostic use for several years after the onset of hyperglycaemia in adult autoimmune patients [26]. LADA patients may otherwise be clinically indistinguishable from those with type 2 diabetes (diagnosed as adults, can be obese) and can be adequately managed for many years with diet/oral agent therapy [3]. However, the GADA-positive cohort contained fewer individuals with features of the metabolic syndrome, a characteristic more typical of classic type 2 diabetes than LADA $[27,28]$. It has been proposed that LADA patients with high GADA levels have a more 'type 1 diabetic' phenotype (reduced residual beta cell function, lower BMI and lower frequency of hypertension), and those with low levels a more type 2 diabetes phenotype [29]. Such subgroups of LADA, based on clinical characteristics, could not be differentiated by GADA level in our cohort. Our findings support results in Australian LADA patients, where high GADA levels did not associate with younger age, shorter duration of disease, leaner body mass or metabolic control compared with those with lower levels [30]. In addition, change in GADA levels over time did not correlate with any alterations in clinical characteristics.

GADA levels did not act as predictive markers of the aggressiveness of the underlying immune pathology as indicated by deterioration of blood glucose control. In the UKPDS, monotherapy failure and requirement for insulin therapy were determined by the protocol and therefore uniform across all patients. Patients with high GADA levels at 0.5 years were more likely to have required additional anti-hyperglycaemic therapy (but not necessarily insulin) by this time point, but GADA levels at 0.5 years were not associated with clinical requirement for insulin therapy between 0.5 and 6 years (Fig. 2b). Moreover subsequent monotherapy failure between 0.5 and 6 years was unrelated to GADA levels at 0.5 years (Fig. 2a). Although this is the largest well-characterised LADA cohort, detailed analyses of monotherapy failure in relationship to GADA levels can only be considered as indicative, since sample sizes were insufficient to provide adequate statistical power. Overall, however, the data suggest that monitoring GADA levels after the diagnosis of diabetes can be useful for the correct identification of LADA but does not add any further contribution for therapy management decisions.

GAD65 epitope recognition Recognition of conformational epitopes of GAD65 has been proposed as a marker for maturation of the humoral response in preclinical phases of type 1 diabetes $[10,31]$ and suggested as a method for differentiation of disease and/or progression in adult-onset diabetes [12, 31-33]. In our cohort, the C-terminal and middle regions of GAD65 contained the most frequently targeted epitopes (in more than $50 \%$ of patients) for samples taken at all time points after diagnosis, whereas $\mathrm{N}$-terminal reactivity was uncommon $(<9 \%)$. There was no evidence of epitope spreading from the middle to the $\mathrm{C}$ - or $\mathrm{N}$-terminal regions with time after diagnosis and no relationship of specific epitope reactivity to disease progression or time to clinical requirement for insulin therapy.

In adult-onset autoimmune patients it is possible that the continuing autoimmune response diminishes the beta cell 
reserve to below a critical functional mass, resulting in decline of insulin secretion. Although GADA levels at diagnosis can help to predict the need for insulin therapy within the next 6 years $[7,22]$ subsequent GADA measurements and fluctuations in levels are not indicators of disease progression or therapy requirement. Genetic and autoimmune markers in LADA indicate a similar aetiology to juvenile-onset diabetes $[5,23,34,35]$ but these markers do not provide important aids to clinical management of LADA patients.

Acknowledgements Funding for the GADA study was provided by Diabetes UK. Support from the Wellcome Trust (A. Clark) is acknowledged. Carole Cull died in June 2007. We would like to recognise her outstanding dedication and commitment to the appropriate and accurate publication of UKPDS data over a period of 20 years. She will be sorely missed by her colleagues and the scientific community at large. The co-operation of the patients for the different studies and many NHS and non-NHS staff at the centres is much appreciated. The major grants for the UKPDS were from the UK Medical Research Council, the British Diabetic Association, the UK Department of Health, the National Eye Institute and the National Institute of Digestive, Diabetes and Kidney Disease in the National Institutes of Health (USA), the British Heart Foundation, NovoNordisk, Bayer, Bristol Myers Squibb, Hoechst, Lilly, Lipha and Farmitalia Carlo Erba. Other funding companies and agencies, the supervising committees, and all participating staff are listed in an earlier publication [36].

Duality of interest The authors declare that there is no duality of interest associated with this manuscript.

\section{References}

1. Alberti KG, Zimmet PZ (1998) Definition, diagnosis and classification of diabetes mellitus and its complications. Part 1: diagnosis and classification of diabetes mellitus provisional report of a WHO consultation. Diabet Med 15:539-553

2. Gottsater A, Ahmed M, Lilja B, Fernlund P, Sundkvist G (1996) Islet cell antibodies at diagnosis, but not leanness, relate to a better cardiovascular risk factor profile 5 years after diagnosis of NIDDM. Diabetes Care 19:60-63

3. Davis TM, Wright AD, Mehta ZM et al (2005) Islet autoantibodies in clinically diagnosed type 2 diabetes: prevalence and relationship with metabolic control (UKPDS 70). Diabetologia 48:695-702

4. Horton V, Stratton I, Bottazzo GF et al (1999) Genetic heterogeneity of autoimmune diabetes: age of presentation in adults is influenced by HLA DRB1 and DQB1 genotypes (UKPDS 43). UK Prospective Diabetes Study (UKPDS) Group. Diabetologia 42:608-616

5. Desai M, Zeggini E, Horton VA et al (2007) An association analysis of the HLA gene region in latent autoimmune diabetes in adults. Diabetologia 50:68-73

6. Sabbah E, Savola K, Kulmala P et al (1999) Diabetes-associated autoantibodies in relation to clinical characteristics and natural course in children with newly diagnosed type 1 diabetes. The Childhood Diabetes In Finland Study Group. J Clin Endocrinol Metab 84:1534-1539
7. Turner R, Stratton I, Horton V et al (1997) UKPDS 25: autoantibodies to islet-cell cytoplasm and glutamic acid decarboxylase for prediction of insulin requirement in type 2 diabetes. UK Prospective Diabetes Study Group. Lancet 350:1288-1293

8. UKPDS Group (1991) UK Prospective Diabetes Study (UKPDS). VIII. Study design, progress and performance. Diabetologia 34:877-890

9. Turner RC, Cull CA, Frighi V, Holman RR (1999) Glycemic control with diet, sulfonylurea, metformin, or insulin in patients with type 2 diabetes mellitus: progressive requirement for multiple therapies (UKPDS 49). UK Prospective Diabetes Study (UKPDS) Group. JAMA 281:2005-2012

10. Bonifacio E, Lampasona V, Bernasconi L, Ziegler AG (2000) Maturation of the humoral autoimmune response to epitopes of GAD in preclinical childhood type 1 diabetes. Diabetes 49: 202-208

11. Hatfield EC, Hawkes CJ, Payton MA, Christie MR (1997) Cross reactivity between IA-2 and phogrin/IA-2beta in binding of autoantibodies in IDDM. Diabetologia 40:1327-1333

12. Piquer S, Belloni C, Lampasona V et al (2005) Humoral autoimmune responses to glutamic acid decarboxylase have similar target epitopes and subclass that show titer-dependent disease association. Clin Immunol 117:31-35

13. (UKPDS). UPDS (1994) XI: Biochemical risk factors in type 2 diabetic patients at diagnosis compared with age-matched normal subjects. Diabet Med 11:534-544

14. Levy JC, Matthews DR, Hermans MP (1998) Correct homeostasis model assessment (HOMA) evaluation uses the computer program. Diabetes Care 21:2191-2192

15. Matthews DR, Hosker JP, Rudenski AS et al (1985) Homeostasis model assessment: insulin resistance and beta-cell function from fasting plasma glucose and insulin concentrations in man. Diabetologia 28:412-419

16. Expert Panel on Detection, Evaluation and Treatment of High Blood Cholesterol in Adults (2001) Executive summary of the third report of the National Cholesterol Education Program (NCEP) Expert Panel on Detection, Evaluation and Treatment of High Blood Cholesterol in Adults (Adult Treatment Panel III). JAMA 285:2486-2497

17. Borg H, Gottsater A, Fernlund P, Sundkvist G (2002) A 12-year prospective study of the relationship between islet antibodies and beta-cell function at and after the diagnosis in patients with adultonset diabetes. Diabetes 51:1754-1762

18. Hampe CS, Hammerle LP, Bekris L et al (2002) Stable GAD65 autoantibody epitope patterns in type 1 diabetes children five years after onset. J Autoimmun 18:49-53

19. Christie MR, Daneman D, Champagne P, Delovitch TL (1990) Persistence of serum antibodies to $64,000-\mathrm{Mr}$ islet cell protein after onset of type I diabetes. Diabetes 39:653-656

20. Pipeleers D, Ling Z (1992) Pancreatic beta cells in insulindependent diabetes. Diabetes Metab Rev 8:209-227

21. Shimada A, Imazu Y, Morinaga S et al (1999) T-cell insulitis found in anti-GAD65+ diabetes with residual beta-cell function. A case report. Diabetes Care 22:615-617

22. Bottazzo GF, Bosi E, Cull CA et al (2005) IA-2 antibody prevalence and risk assessment of early insulin requirement in subjects presenting with type 2 diabetes (UKPDS 71). Diabetologia 48:703-708

23. Gale EAM (2006) Declassifying diabetes. Diabetologia 49:19891995

24. Batstra MR, Pina M, Quan J et al (1997) Fluctuations in GAD65 antibodies after clinical diagnosis of IDDM in young children. Diabetes Care 20:642-644

25. Savola K, Sabbah E, Kulmala P et al (1998) Autoantibodies associated with Type I diabetes mellitus persist after diagnosis in children. Diabetologia 41:1293-1297 
26. Castleden HA, Shields B, Bingley PJ et al (2006) GAD antibodies in probands and their relatives in a cohort clinically selected for Type 2 diabetes. Diabet Med 23:834-838

27. Hosszufalusi N, Vatay A, Rajczy K et al (2003) Similar genetic features and different islet cell autoantibody pattern of latent autoimmune diabetes in adults (LADA) compared with adult-onset type 1 diabetes with rapid progression. Diabetes Care 26:452-457

28. Tuomi T, Carlsson A, Li H et al (1999) Clinical and genetic characteristics of type 2 diabetes with and without GAD antibodies. Diabetes 48:150-157

29. Lohmann T, Kellner K, Verlohren HJ et al (2001) Titre and combination of ICA and autoantibodies to glutamic acid decarboxylase discriminate two clinically distinct types of latent autoimmune diabetes in adults (LADA). Diabetologia 44:10051010

30. Davis TM, Zimmet P, Davis WA et al (2000) Autoantibodies to glutamic acid decarboxylase in diabetic patients from a multiethnic Australian community: the Fremantle Diabetes Study. Diabet Med 17:667-674

31. Padoa CJ, Banga JP, Madec AM et al (2003) Recombinant Fabs of human monoclonal antibodies specific to the middle epitope of
GAD65 inhibit type 1 diabetes-specific GAD65Abs. Diabetes 52:2689-2695

32. Falorni A, Gambelunghe G, Forini F et al (2000) Autoantibody recognition of $\mathrm{COOH}$-terminal epitopes of GAD65 marks the risk for insulin requirement in adult-onset diabetes mellitus. J Clin Endocrinol Metab 85:309-316

33. Kobayashi T, Tanaka S, Okubo M et al (2003) Unique epitopes of glutamic acid decarboxylase autoantibodies in slowly progressive type 1 diabetes. J Clin Endocrinol Metab 88:4768-4775

34. Desai M, Clark A (2006) Comment on Gale EAM (2005) Latent Autoimmune diabetes in adults: a guide for the perplexed. Diabetologia 49:2222

35. Desai M, Zeggini E, Horton VA et al (2006) The variable number of tandem repeats upstream of the insulin gene is a susceptibility locus for latent autoimmune diabetes in adults. Diabetes 55:1890 1894

36. UKPDS Group (1998) Intensive blood-glucose control with sulphonylureas or insulin compared with conventional treatment and risk of complications in patients with type 2 diabetes (UKPDS 33). UK Prospective Diabetes Study (UKPDS) Group. Lancet $352: 837-853$ 